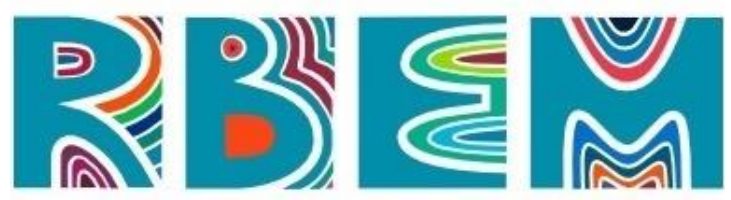

REVISTA BAIANA DE EDUCAÇÃO MATEMÁTICA

ARTIGO

https://doi.org/10.47207/rbem.v2i01.12370

\title{
Para além das aparências: desafios e percepções diante da oferta do Estágio Supervisionado na Licenciatura em Matemática do IFCE campus Cedro no contexto do ensino remoto
}

\author{
LIMA, Francisco José de \\ IFCE campus Cedro. Doutor em Educação. https://orcid.org/0000-0001-5758-5159.E-mail. \\ franciscojose@ifce.edu.br \\ SILVA, Roberta da \\ IFCE campus Cedro. Doutora em Psicologia. https://orcid.org/0000-0001-5620-975X. E-mail. \\ robertasilva@ifce.edu.br
}

\begin{abstract}
Resumo: O presente estudo tem como objetivos descrever e discutir estratégias de ações para a oferta das disciplinas de Estágios Supervisionados no formato remoto, como alternativa face ao período de suspensão das atividades de ensino realizadas presencialmente. Com abordagem qualitativa, o trabalho caracteriza-se como estudo de caso e tomou como objeto de análise documentos que tratam sobre a retomada do componente curricular nas licenciaturas, com enfoque analítico no plano de trabalho do curso de Matemática do IFCE, campus Cedro e seus desdobramentos. As discussões apontam proposições e orientações institucionais para a realização dos estágios no formato remoto e seu respectivo plano de execução no curso, discorrendo sobre memórias, desafios e percepções de futuros professores, ressaltando-se a impossibilidade de encontros para planejamento com professores formadores e professores regentes assim, como o impedimento da convivência com o ambiente pedagógico da escola e suas rotinas de trabalho. Além desses aspectos, destacam-se a falta de estrutura para o trabalho remoto, principalmente no que se refere às condições, como energia elétrica, acesso à internet, computadores e aparelhos celulares, além de ausência de espaços adequados em domicílios da maioria desses professores e estudantes, elementos que implicam em dificuldades e limitações para a realização do trabalho pedagógico e, consequentemente, do Estágio Supervisionado em Matemática. Palavras-chave: Estágio Supervisionado. Ensino Remoto. Pandemia.

\section{Beyond appearances: challenges and perceptions in view of the offer of supervised internship in the Degree in Mathematics of IFCE Cedro campus in the context of remote education}

\begin{abstract}
The present study aims to describe and discuss action strategies for the provision of supervised internship disciplines in the remote format, as an alternative to the suspension period of classroom teaching activities. With a qualitative approach, the work is characterized as a case study and took as object of analysis documents that deal with the resumption of the curricular component in undergraduate degrees, focusing on analysis in the work plan of the Mathematics course of IFCE, Cedro campus and its developments. The discussions point to institutional propositions and guidelines for the realization of internships in the remote format and their respective execution plan in the course, discussing memories, challenges and perceptions of future teachers, highlighting the impossibility of meetings for planning with teacher trainers and teachers regents as well, as the impediment of living with the pedagogical environment of the school and its work routines. In addition to these aspects, we highlight the lack of structure for remote work, mainly, electricity, internet access, computers and
\end{abstract}




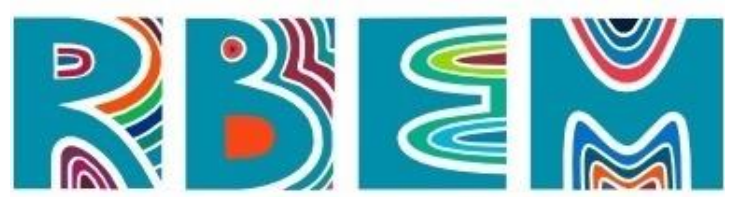

REVISTA BAIANA DE EDUCAÇÃO MATEMÁTICA

cellular devices, in addition to the absence of adequate spaces in the homes of most of these teachers and students, elements that imply difficulties and limitations for the performance of pedagogical work and, consequently, of the supervised internship in Mathematics.

Keywords: Supervised Internship. Remote Teaching. Pandemic.

\section{Más allá de las apariencias: retos y percepciones ante la oferta de prácticas supervisadas en el Grado en Matemáticas del IFCE campus Cedro en el contexto de la educación a distancia}

Resumen: El presente estudio tiene como objetivo describir y discutir estrategias de acción para la provisión de disciplinas de prácticas supervisadas en formato remoto, como alternativa al período de suspensión de las actividades de enseñanza en el aula. Con un enfoque cualitativo, el estudio se caracteriza como un estudio de caso y se toma como objeto de análisis documentos que tratan de la reanudación del componente curricular en las licenciaturas, centrándose en el análisis en el plan de trabajo del curso de Matemáticas de ifce, cedar campus y sus consecuencias. Las discusiones apuntan a propuestas institucionales y lineamientos para la realización de pasantías en formato remoto y su respectivo plan de ejecución en el curso, discutiendo recuerdos, desafíos y percepciones de los futuros docentes, destacando la imposibilidad de reuniones de planificación con formadores de maestros y regentes docentes, así como el impedimento de convivimiento con el ambiente pedagógico de la escuela y sus rutinas de trabajo. Además de estos aspectos, destacamos la falta de estructura para el trabajo remoto, principalmente, electricidad, acceso a internet, computadoras y dispositivos celulares, además de la ausencia de espacios adecuados en los hogares de la mayoría de estos profesores y estudiantes, elementos que implican dificultades y limitaciones para el desempeño del trabajo pedagógico y, en consecuencia, de las prácticas supervisadas en Matemáticas.

Palabras clave: Prácticas supervisadas. Enseñanza remota. Pandemia.

\section{Introdução}

No ano de 2020, desde o momento em que o coronavírus SARS-Cov2 foi caracterizado pela Organização Mundial da Saúde (OMS) resultando na pandemia da COVID-19 (OMS, 2020), o mundo tem enfrentado inúmeros desafios e, com isso, a população tem vivenciado dias difíceis e incertos. Imersos no turbilhão de efeitos oriundos dessa pestilência, tornou-se impossível não tratar sobre $\mathrm{o}$ assunto considerando as consequências cruéis do novo coronavírus que assolou nações, agravou velhas assimetrias de ordem humano-social espalhando medo generalizado e ceifando vidas sem fronteiras.

Nesse contexto, a crise pandêmica, invariavelmente, evaporou "a segurança de um dia para o outro" (SANTOS, 2020, p.7), trazendo à tona a necessidade de isolamento social, a fim de evitar a disseminação da doença, medida que implicou diretamente na economia global. Esse cenário permitiu ao mundo ver o neoliberalismo ajoelhando-se para a pesquisa e para a ciência como caminhos sistemáticos e eficazes para o enfrentamento e contenção da pandemia, embora se observe "crescente aceitação social do negacionismo científico e à 


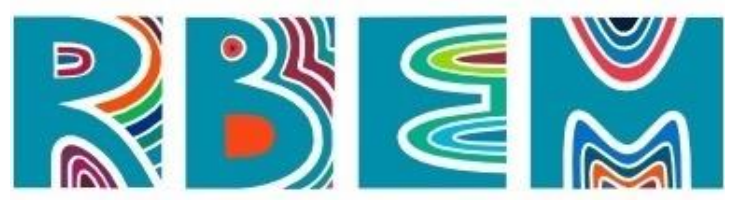

REVISTA BAIANA DE EDUCAÇÃO MATEMÁTICA

desconsideração de argumentos racionais em diversos âmbitos" (CAPONI, 2020, p. 2010), é preciso resgatar a defesa da ciência, a favor da vida, contra o obscurantismo científico (ALESSI; et al., 2021).

Apoiados em orientações de órgãos e autoridades sanitárias, como a Organização Mundial de Saúde (OMS), para evitar a propagação do vírus, governos de todo o mundo fecharam, temporariamente, instituições educacionais provocando impacto em mais de $70 \%$ da população estudantil do mundo (UNESCO, 2020). A paralisação das aulas presenciais e, consequentemente, a interrupção de calendários letivos, embora necessárias, causaram certa instabilidade nos processos escolares, "sendo incerto o seu impacto sobre o aprendizado dos alunos" (OLIVEIRA; GOMES e BARCELLOS, 2020, p.555).

Mesmo como medida necessária, a suspensão de calendários letivos presenciais, proporcionou forte repercussão aos contextos acadêmicos e, posteriormente, implicou em reflexões e debates quanto à definição de possibilidades e estratégias de trabalho pedagógico para o desenvolvimento dos processos de ensino e aprendizagem.

No contexto dos cursos de Licenciatura, os Estágios Supervisionados são componentes da dimensão prática que se constituem em espaços privilegiados para o desenvolvimento da aprendizagem da profissão docente e de construção da identidade profissional do professor, a

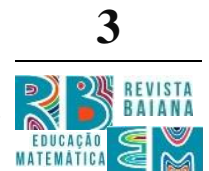
partir da interação com a escola e seus interlocutores (LIMA, 2012).

Para Pimenta e Lima (2005-2006), embora o estágio tenha sido percebido ao longo do tempo como "a parte prática dos cursos de formação de professores", o mesmo deve ser compreendido como campo epistemológico, rompendo com o significado recorrente de saber instrumental, desenvolvido a partir de atividades meramente práticas. Na contramão desse entendimento ainda muito presente nos cursos de formação inicial, a construção deste estudo dialoga com uma definição de estágio que o aponta como produto de interações entre os cursos de formação e os contextos onde as práticas educativas são desenvolvidas.

A aprendizagem docente vem sendo foco de estudo do Grupo Interdisciplinar de Pesquisa em Ensino e Aprendizagem (GIPEA) ${ }^{1}$, especialmente na Linha de Pesquisa “Trabalho Docente, Formação de Professores e Políticas Educacionais", nas pesquisas e reflexões desenvolvidas nos últimos dez anos. Particularmente, tem-se centrado em

\footnotetext{
${ }^{1}$ Nossas pesquisas têm sido financiadas por Editais Internos da Pró-reitora de Pesquisa, Pós-Graduação e Inovação (PRPI) e Editais do Programa de Estudante Voluntário em Pesquisa e Inovação - PEVPI
} 


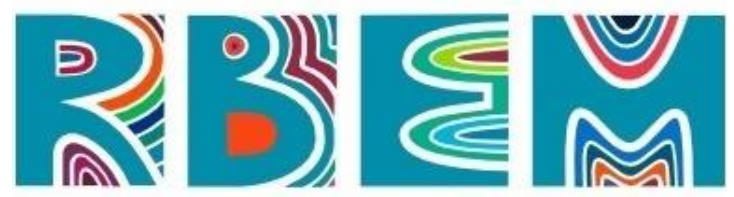

REVISTA BAIANA DE EDUCAÇÃO MATEMÁTICA

compreender processos, espaços e tempos que compõem a tessitura do constituir-se professor de Matemática na/para a Educação Básica.

Nesse sentido, quando ventilada a possibilidade de oferta desses componentes curriculares no modo remoto, as tensões e os debates se intensificaram entre professores(as) e licenciandos(as). Para o enfrentamento dessa questão, fizeram-se necessárias exaustivas reuniões virtuais que resultaram em uma proposta aprovada pelo colegiado do curso, incluindo experiências pedagógicas que buscaram compreender o fenômeno da sala de aula colocando em prática outros conhecimentos, habilidades e competências do(a) educador(a) matemático(a) e a elaboração de relatos de experiência, considerando as especificidades vivenciadas por ocasião do ensino remoto.

Diante desse contexto atípico, este estudo busca responder: como os Estágios Supervisionados foram redimensionados na perspectiva de adequar ações formativas de professores para o ensino de Matemática, diante de desafios impostos pelo ensino remoto emergencial? Que metodologias de ensino e recursos pedagógicos estão sendo utilizados, na expectativa de atender necessidades de aprendizagem de estudantes?

Para atender esses questionamentos, optou-se por utilizar a abordagem qualitativa, empregando o estudo de caso como método de pesquisa, depreendido por Yin $(2005$, p. 32) como "uma investigação empírica que investiga um fenômeno contemporâneo dentro de seu contexto de vida real, especialmente quando os limites entre o fenômeno e o contexto não estão claramente definidos", permitindo verificar fatos presentes na contemporaneidade.

Desse modo, o estudo tem por objetivos descrever e discutir sobre estratégias de ação para a oferta das disciplinas de Estágio Supervisionado no modo remoto em um curso de Licenciatura em Matemática, no contexto da suspensão das atividades presenciais no IFCE, enquanto durarem as medidas restritivas de isolamento social por conta da pandemia do SarsCoV-2 (COVID-19), em conformidade com documentos institucionais e demais bases legais.

\section{Estágio Supervisionado e formação docente}

Nas últimas décadas, a formação inicial de professores para a Educação Básica em cursos de licenciaturas e suas nuances têm sido pauta de debates e pesquisas que apontam apreensão em relação à qualidade formativa e a melhores condições para o exercício profissional. Não obstante, atualmente, esse campo de estudo tem concentrado muito mais 


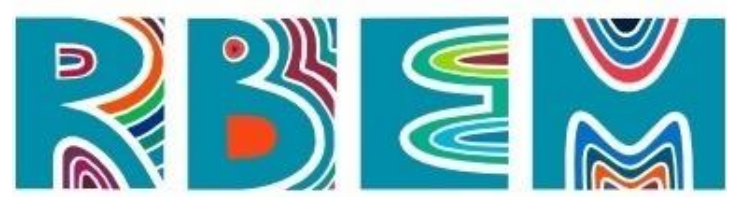

REVISTA BAIANA DE EDUCAÇÃO MATEMÁTICA

atenção diante de assimetrias socioculturais e de desafios postos ao fazer docente (GATTI, et. al. 2014; 2019).

A partir da promulgação da Lei de Diretrizes e Bases da Educação Nacional -Lei no 9394/96 (BRASIL, 1996), a Resolução CNE/CP n 2 de 2015 e até as recentes revisões e atualizações dessa Resolução propostas na Resolução CNE/CP n $^{\circ}$ 2, de 20 de dezembro de 2019 que define as Diretrizes Curriculares Nacionais para a Formação Inicial de Professores para a Educação Básica e institui a Base Nacional Comum para a Formação Inicial de Professores da Educação Básica (BRASIL, 2019), observa-se que a formação de professores constitui-se em um desafio tanto para políticas públicas governamentais, quanto para espaços formativos de professores.

As ações do Plano Nacional de Formação de Professores (Programa Institucional de Bolsa de Iniciação à Docência - PIBID; Observatório da Educação - OBEDUC; Programa de Consolidação das Licenciaturas - PRODOCÊNCIA; Programa Residência Pedagógica PRP) são entendidas como insuficientes, pois além de atender uma pequena parcela de licenciandos, "não respondem pelas condições objetivas de trabalho que justificam a significativa evasão de professores da Educação Básica. A contradição entre o discurso da importância da formação e a precariedade do exercício da profissão permanece" (LIMA, 2018, p. 50).

Mesmo diante da limitação expressa, compreende-se, assim como Reis, André e Passos (2020, p. 38) que, ao tratar da regulamentação das ações para a formação de professores no contexto educacional brasileiro, infere-se que as políticas criadas pelo Estado "legitimam o vínculo entre as Instituições de Ensino Superior (IES) formadoras e as escolas, colocando a formação do professor como elemento importante na visualização de melhoria da qualidade da educação".

Ao se voltar para o preparo específico da docência, as Diretrizes Curriculares Nacionais para a Formação de Professores da Educação Básica (BRASIL, 2019), em nível superior, apontam que a formação docente exige um conjunto de conhecimentos, habilidades, valores e atitudes que precisam estar alicerçados na prática, necessitando ir além de momentos de estágio obrigatório, devendo estar presente desde o início do curso, tanto nos conteúdos educacionais e pedagógicos, quanto nos conteúdos específicos da área do conhecimento. 


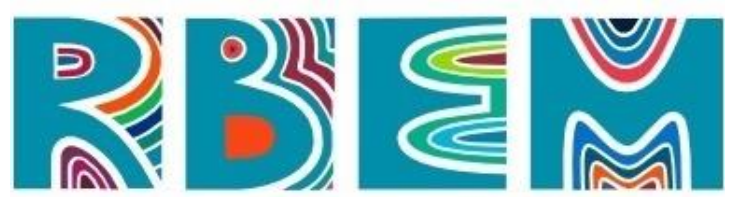

REVISTA BAIANA DE EDUCAÇÃO MATEMÁTICA

Na perspectiva de Marcon (2011), no que diz respeito ao percurso das práticas nos cursos de formação inicial, os estágios ocupam lugar de relevância em que os licenciandos se aproximam do contexto da escola e, principalmente, aproximam-se da atuação profissional docente. No entanto, ainda no entendimento do autor, as práticas devem se desenvolver ao longo da formação, afastando-se da compreensão de que o estágio é o período da formação reservado à aplicação dos conhecimentos teóricos, o que agrega extrema responsabilidade aos estagiários no final do processo formativo. Para Marcon (2011), essa compreensão fortalece o entendimento de que o estágio é o principal responsável pela formação pedagógica dos futuros professores, causando-lhes um abrupto choque de realidade, certa frustração, sensação de que estão mal preparados, sentimento de impotência e incertezas quanto ao futuro exercício profissão.

Nesse sentido, os cursos de licenciaturas são cenários e contextos de formação docente para a Educação Básica, sendo um de seus objetivos propiciar subsídios teóricos e práticos, cuja articulação mostra-se necessária à prática profissional, a qual deve ser oportunizada para além dos Estágios Supervisionados, inclusive precedendo-os, considerando-se cada área de conhecimento. No âmbito dos Institutos Federais, a oferta de licenciaturas foi estabelecida na própria legislação que os originou (Lei $\mathrm{n}^{\circ}$ 11.892/2008), estabelecendo em um de seus objetivos: “ministrar em nível de Educação Superior [...] b) curso de licenciatura, bem como programas especiais de formação pedagógicas, com vistas na formação de professores para a Educação Básica, sobretudo nas áreas de Ciências e Matemática, e para a Educação Profissional [...] (BRASIL, 2008).

Nessa perspectiva, no contexto do curso de Licenciatura em Matemática do Instituto Federal de Educação, Ciência e Tecnologia do Ceará, IFCE campus Cedro, corrobora-se com Pimenta e Lima (2005/2006), ao assumir também que o estágio se constitui em um campo de conhecimento,

[...] o que significa atribuir-lhe um estatuto epistemológico que supera sua tradicional redução à atividade prática instrumental. Enquanto campo de conhecimento, o estágio se produz na interação dos cursos de formação com o campo social no qual se desenvolvem as práticas educativas. Nesse sentido, o estágio poderá se constituir em atividade de pesquisa (PIMENTA, LIMA, 2005/2006, p. 6).

Assim, as licenciaturas como cursos de formação docente, em suas propostas formativas, de modo particular nos componentes de Estágio Supervisionado, precisam 


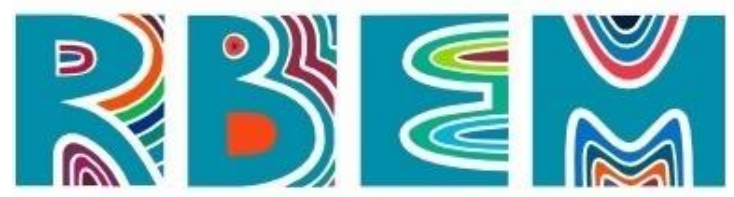

REVISTA BAIANA DE EDUCAÇÃO MATEMÁTICA

promover atividades que permitam a análise, a reflexão e o conhecimento da cultura escolar e da cultura docente, abordando suas ações, trabalho, desafios e impasses, possibilitando ao licenciando ampla compreensão do contexto escolar.

Considerando esses pressupostos, admite-se que o Estágio Supervisionado oportuniza ao professor em formação inicial conhecer, analisar e refletir sobre seu futuro ambiente de trabalho, sendo necessário observar que "as atividades desenvolvidas no decorrer do curso de formação considerem o estágio como um espaço privilegiado de questionamento e investigação" (PIMENTA; LIMA, 2012, p. 112).

É inquestionável que as atividades de estágios supervisionados implicam em vivências e interações em escolas de Educação Básica. Os(as) licenciandos(as), ao interagirem com a realidade, acabam refletindo sobre as ações observadas e partilhadas no contexto em que estão inseridos, desenvolvendo suas próprias formas de ser e agir como futuros professores. Esse tempo/espaço constitui-se de momentos oportunos para articular saberes necessários à docência, permitindo pensar e explorar demandas impostas diariamente na sala de aula (SILVA, GASPAR, 2018).

Com o surgimento da pandemia da COVID-19, o convívio foi rompido e as atividades educacionais assumiram, em caráter emergencial, o modo remoto. Saviani e Galvão (2021) ) apontam que a decisão pela oferta dessa estratégia de ensino foi uma escolha política que desconsiderou desigualdades do contexto educacional brasileiro, pois os sistemas de ensino precisaram se adaptar ao ensino remoto, sendo que, depois de três meses da suspensão das aulas presenciais, boa parte das redes de ensino não desenvolviam atividades à distância.

Esse cenário implicou em mudanças vividas pelos(as) docentes em relação aos processos de ensino e aprendizagem, principalmente quanto aos modos e condições de atuação de professores, uma vez que o ensino remoto exige mais tempo de trabalho, o que tem provocado fadiga tecnológica em discentes e docentes. Essa exaustão se deve ao uso contínuo de meios tecnológicos para dar contas de compromissos escolares e de trabalho, gerando esforço intenso, o que pode prejudicar as atividades diárias tanto no âmbito escolar quanto profissional.

Dentre os desafios enfrentados, destacam-se a responsabilidade própria de aquisição de equipamentos e conexão para o desenvolvimento de aulas, falta de acesso e suporte tecnológico, pouca experiência com o uso das ferramentas digitais em sala de aula, falta de 


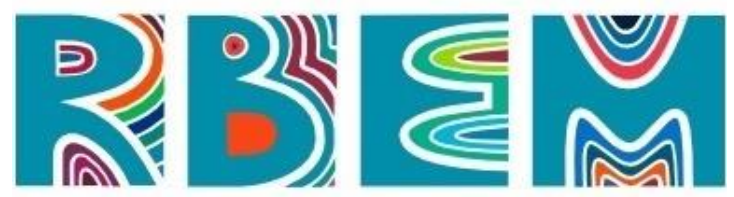

REVISTA BAIANA DE EDUCAÇÃO MATEMÁTICA

capacitação prévia para esse uso e realização do trabalho remoto e situação de vulnerabilidade de muitas famílias de estudantes.

Em meio a medos e lutas por sobrevivência, provados pela pandemia, professores, alunos e famílias tiveram de readequar seus modos vida e de trabalho para atender às demandas de atividades não presenciais. Conforme Ferreira e Barbosa (2020, p. 10) as "mudanças empreendidas na organização do trabalho e na organização escolar atualmente são profundas e exigem reorientação da vida pessoal e profissional".

\section{Percurso Metodológico}

A pesquisa caracteriza-se como qualitativa e foi desenvolvida mediante estudo de caso, tendo como estratégias de coletas de dados a pesquisa documental e experiências iniciais vivenciadas pelos autores com as primeiras turmas de Estágio Supervisionado ofertadas no formato remoto. Na primeira etapa do presente estudo, foram analisados a normativa institucional que trata das atividades de estágio supervisionado nas licenciaturas e o

plano de trabalho do curso de Matemática do IFCE, campus Cedro. A segunda etapa teve como enfoque as experiências proporcionadas pelas atividades inicialmente desenvolvidas.

Os dados coletados foram analisados mediante a análise de conteúdo de Bardin (2011), seguindo as etapas de pré-análise, exploração do material e tratamento dos resultados - inferência. Na etapa de pré-análise, foram observadas as regras da exaustividade, representatividade, homogeneidade, pertinência e exclusividade (BARDIN, 2011), considerando-se as questões que direcionaram o presente estudo, organizando os dados coletados para a etapa de exploração do material e interpretação. Na etapa de exploração do material, os dados foram analisados, resguardando-se os objetivos estabelecidos para a pesquisa e, na última etapa, procedeu-se à inferência e à interpretação dos achados, buscandose agregar significado e validade aos dados coletados e explorados.

Os resultados estão apresentados em três seções, discutindo-se, inicialmente, as proposições e orientações institucionais para a realização dos Estágios Supervisionados no formato remoto; na sequência, apresenta-se e se analisa o plano de trabalho para o desenvolvimento das disciplinas de estágio no âmbito da observação e regência e, na última seção, relatam-se as memórias, desafios e percepções acerca do desenvolvimento das 


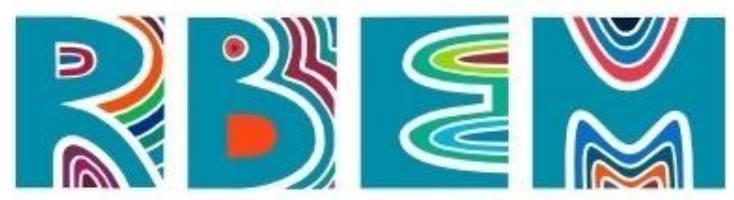

REVISTA BAIANA DE EDUCAÇÃO MATEMÁTICA

atividades até então realizadas, evidenciando-se aspectos centrais diante do objetivo proposto para o presente estudo.

\section{O Estágio Supervisionado nas licenciaturas do IFCE: proposições e orientações institucionais para a realização no formato remoto}

As orientações institucionais, expressas no Ofício Conjunto Circular $n^{\circ}$ 1/2021 PROEN/PRPI/PROEXT/REITORIA, fundamentam-se nas portarias do Ministério da Educação-MEC, № 1.030 de 01 dezembro de 2020; 1.038 de 07 de dezembro de 2020 e 1.096 de 31 de dezembro de 2020, bem como no Decreto Estadual que prorroga o período de isolamento social em decorrência da pandemia. De acordo com o documento, cabe aos Colegiados de cursos a definição sobre a oferta do estágio no formato remoto, assim como a aprovação dos planos de trabalhos elaborados pelos docentes das disciplinas, os quais deverão ser anexados aos Projetos Pedagógicos dos Cursos - PPC's.

Os planos de trabalho devem apresentar as metodologias a serem adotadas, bem como a infraestrutura e recursos de promoção da interação de forma remota. Os planos devem seguir as orientações constantes nos anexos do referido ofício e, após a aprovação do Colegiado dos cursos e anexados aos PPC, eles deverão ser encaminhados à gestão máxima do ensino para validação e encaminhamento à Pró-reitora de Ensino-PROEN, que precisará enviá-los ao MEC.

O Ofício Conjunto Circular no 3/2021 PROEN/REITORIA, de 07 de abril de 2021 dispõe especificamente acerca do estágio remoto nas licenciaturas, com base legal no ofício de $\mathrm{N}^{\circ}$ 01/2021 e no Parecer CNE/CP No 05/2020. O documento orienta que o planejamento deverá ser realizado mediante discussões entre corpo docente, técnicos administrativos e corpo discente, em articulação com as escolas de educação básica, as quais representam os espaços de realização dos estágios das licenciaturas.

Mediante as orientações do ofício $\mathrm{n}^{\circ}$ 03, a elaboração dos planos de trabalho deverá contar com a parceria das escolas de educação básica, considerando a realidade dessas escolas no contexto da pandemia, no intuito de definir coletivamente as atividades possíveis de realização, prevendo ainda a realização de atividades de extensão, desde que em parceria com 


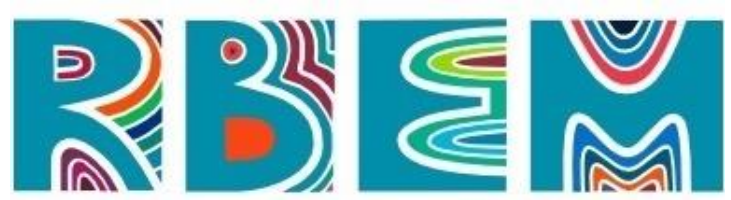

REVISTA BAIANA DE EDUCAÇÃO MATEMÁTICA

as escolas. No que competem às atividades de extensão, estas não deverão ser cadastradas institucionalmente, a fim de evitar duplicidade de contabilização de carga horária docente.

Dentre as atividades propostas para a realização do estágio de forma remota, destacam-se: observação e regência; rodas de conversas com egressos dos cursos e dos programas PIBID e PRP; reuniões de planejamento; projetos de intervenção; elaboração de materiais; atividades de pesquisa e extensão.

\section{Plano de Trabalho para realização de Estágios Supervisionados na Licenciatura em Matemática do IFCE, campus Cedro}

Considerando as orientações institucionais quanto à realização de Estágios Supervisionados em cursos de licenciaturas no contexto de pandemia e observando a organização curricular do curso de Licenciatura em Matemática, cuja carga horária totaliza 440 horas distribuídas em Estágio Supervisionado I (Observação e participação), Estágio Supervisionado II (Regência de sala de aula) - ambos no Ensino Fundamental-, Estágio Supervisionado III (Observação e participação) e Estágio Supervisionado IV (Regência de sala de aula) - ambos no Ensino Médio, o plano de trabalho apresentado pelos docentes busca adequar-se a essas orientações, estabelecendo, desse modo, as estratégias possíveis para a realização das atividades. No Quadro 1 são apresentados aspectos a serem desenvolvidos nos Estágios Supervisionados no modo remoto, destacando a carga horária a ser cumprida pelos(as) licenciandos(as).

Quadro 1: Os Estágios Supervisionados da Licenciatura em Matemática do IFCE campus Cedro (do ensino presencial ao modo remoto)

\begin{tabular}{|c|c|c|}
\hline Estágio I - Observação no Ensino Fundamental & PRESENCIAL & REMOTO \\
\hline Encontros síncronos com o professor orientador & $40 \mathrm{~h} / \mathrm{a}$ & $50 \mathrm{~h} / \mathrm{a}$ \\
\hline $\begin{array}{l}\text { Observação de aulas síncronas; realização de rodas de } \\
\text { conversas/entrevistas com professores do Ensino Fundamental para } \\
\text { relatos de experiências; rodas de conversa/entrevistas com alunos que } \\
\text { foram bolsistas do PRP; rodas de conversas com os estagiários sobre } \\
\text { suas experiências no Ensino Fundamental. }\end{array}$ & $30 \mathrm{~h} / \mathrm{a}$ & $\begin{array}{l}20 \mathrm{~h} / \mathrm{a} * 10 \mathrm{~h} / \mathrm{a} \\
\text { (mínimo de } \\
\text { observação) }\end{array}$ \\
\hline $\begin{array}{l}\text { Participação em atividades extracurriculares (webinários, seminários, } \\
\text { eventos, planejamentos, reuniões, encontros pedagógicos e projetos } \\
\text { desenvolvidos na/pela escola ou instituição de educação, dentre outros) }\end{array}$ & $10 \mathrm{~h} / \mathrm{a}$ & $20 \mathrm{~h} / \mathrm{a}$ \\
\hline
\end{tabular}




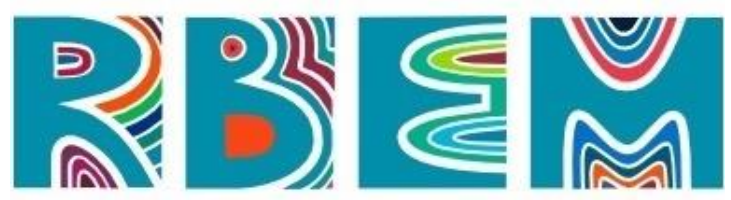

REVISTA BAIANA DE EDUCAÇÃO MATEMÁTICA

\begin{tabular}{|c|c|c|}
\hline Orientações individuais/coletivas e elaboração de relatório final ${ }^{2}$ & $20 \mathrm{~h} / \mathrm{a}$ & $10 \mathrm{~h} / \mathrm{a}$ \\
\hline Carga Horária Total & $100 \mathrm{~h} / \mathrm{a}$ & $100 \mathrm{~h} / \mathrm{a}$ \\
\hline Estágio II - Regência no Ensino Fundamental & PRESENCIAL & REMOTO \\
\hline Encontros síncronos com o professor orientador & $40 \mathrm{~h} / \mathrm{a}$ & $50 \mathrm{~h} / \mathrm{a}$ \\
\hline $\begin{array}{l}\text { Regência de aulas síncronas; construção de material didático (material } \\
\text { de aula, listas de exercícios, produção de vídeos, etc.); realização de } \\
\text { oficina com professores e com alunos. }\end{array}$ & $30 \mathrm{~h} / \mathrm{a}$ & $\begin{array}{l}20 \mathrm{~h} / \mathrm{a} * 10 \mathrm{~h} / \mathrm{a} \\
\text { (mínimo de } \\
\text { regência) }\end{array}$ \\
\hline $\begin{array}{l}\text { Participação em atividades extracurriculares (webinários, seminários, } \\
\text { eventos, planejamentos, reuniões, encontros pedagógicos e projetos } \\
\text { desenvolvidos na/pela escola ou instituição de educação, dentre outros) }\end{array}$ & $10 \mathrm{~h} / \mathrm{a}$ & $20 \mathrm{~h} / \mathrm{a}$ \\
\hline Planejamento de atividades de regência & $20 \mathrm{~h} / \mathrm{a}$ & $20 \mathrm{~h} / \mathrm{a}$ \\
\hline Orientações individuais/coletivas e elaboraç & $20 \mathrm{~h} / \mathrm{a}$ & $10 \mathrm{~h} / \mathrm{a}$ \\
\hline Carga Horária Total & $120 \mathrm{~h} / \mathrm{a}$ & $120 \mathrm{~h} / \mathrm{a}$ \\
\hline Estágio III - Observação no Ensin & PRESENCIAL & REMOTO \\
\hline Encontros síncronos com o professor orientador & $40 \mathrm{~h} / \mathrm{a}$ & $50 \mathrm{~h} / \mathrm{a}$ \\
\hline $\begin{array}{l}\text { Observação de aulas síncronas; realização de rodas de } \\
\text { conversas/entrevistas com professores do Ensino Fundamental para } \\
\text { relatos de experiências; rodas de conversa/entrevistas com alunos que } \\
\text { foram bolsistas do PRP; rodas de conversas com os estagiários sobre } \\
\text { suas experiências no Ensino Fundamental. }\end{array}$ & $30 \mathrm{~h} / \mathrm{a}$ & $\begin{array}{l}20 \mathrm{~h} / \mathrm{a} * 10 \mathrm{~h} / \mathrm{a} \\
(\text { mínimo de } \\
\text { observação) }\end{array}$ \\
\hline $\begin{array}{l}\text { Participação em atividades extracurriculares (webinários, seminários, } \\
\text { eventos, planejamentos, reuniões, encontros pedagógicos e projetos } \\
\text { desenvolvidos na/pela escola ou instituição de educação, dentre outros) }\end{array}$ & $10 \mathrm{~h} / \mathrm{a}$ & $20 \mathrm{~h} / \mathrm{a}$ \\
\hline Orientações individuais/coletivas e elaboração de relatório final & $20 \mathrm{~h} / \mathrm{a}$ & $10 \mathrm{~h} / \mathrm{a}$ \\
\hline Carga Horária Total & $100 \mathrm{~h} / \mathrm{a}$ & $100 \mathrm{~h} / \mathrm{a}$ \\
\hline Estágio IV - Regência no Ensino Médio & PRESENCIAL & REMOTO \\
\hline Encontros síncronos com o professor orientador & $40 \mathrm{~h} / \mathrm{a}$ & $50 \mathrm{~h} / \mathrm{a}$ \\
\hline $\begin{array}{l}\text { Regência de aulas síncronas; construção de material didático (material } \\
\text { de aula, listas de exercícios, produção de vídeos, etc.); realização de } \\
\text { oficina com professores e com alunos. }\end{array}$ & $30 \mathrm{~h} / \mathrm{a}$ & $\begin{array}{l}20 \mathrm{~h} / \mathrm{a} * 10 \mathrm{~h} / \mathrm{a} \\
(\text { mínimo de } \\
\text { regência) }\end{array}$ \\
\hline $\begin{array}{l}\text { Participação em atividades extracurriculares (webinários, seminários, } \\
\text { eventos, planejamentos, reuniões, encontros pedagógicos e projetos } \\
\text { desenvolvidos na/pela escola ou instituição de educação, dentre outros) }\end{array}$ & $10 \mathrm{~h} / \mathrm{a}$ & $20 \mathrm{~h} / \mathrm{a}$ \\
\hline Planejamento de atividades de regência & $20 \mathrm{~h} / \mathrm{a}$ & $200 \mathrm{~h} / \mathrm{a}$ \\
\hline Orientações individuais/coletivas e elaboração de relatório final & $20 \mathrm{~h} / \mathrm{a}$ & $10 \mathrm{~h} / \mathrm{a}$ \\
\hline Carga Horária Total & $120 \mathrm{~h} / \mathrm{a}$ & $120 \mathrm{~h} / \mathrm{a}$ \\
\hline
\end{tabular}

Fonte: Organizado pelos autores, a partir do plano de trabalho (2021).

No que diz respeito ao produto final dos estágios supervisionados, requisito obrigatório para a conclusão da disciplina, o Plano de Trabalho orienta a construção de relatos de experiências, em que o estagiário deverá apresentar as experiências vividas durante a realização das atividades de estágio, cumprindo, para além da obrigatoriedade de sua produção, o papel de promover a reflexão crítica do(a) estagiário(a) acerca das experiências, problematizando aspectos inerentes ao seu futuro contexto de atuação profissional, assumindo

\footnotetext{
${ }^{2}$ Conforme o plano de trabalho para a realização de Estágios Supervisionados no modo remoto do IFCE campus Cedro, o relatório final constituiu-se da escrita de um relato de experiência produzido no formato de artigo científico.
} 


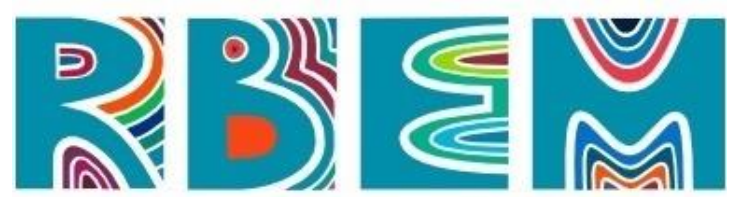

REVISTA BAIANA DE EDUCAÇÃO MATEMÁTICA

a postura de um professor-pesquisador. A construção dos relatos consiste em um momento propício à reflexão, à interpretação, à proposição e, sobretudo, à construção da identidade profissional.

Convém destacar que, dadas as peculiaridades do formato da oferta da disciplina, é imprescindível que as condições de atuação no modo remoto sejam colocadas em debate, tais como acesso à internet, disponibilidade de equipamentos, evidenciando-se dificuldades enfrentadas por professores e estudantes ao longo da experiência, considerando-se, sobretudo, a natureza da atividade de estágio supervisionado e sua função no processo de formação inicial de professores.

De acordo com as orientações expostas, sugere-se a escrita de uma apresentação da escola-campo de atuação do estagiário, destacando o tipo de rede, níveis e modalidades de atendimento, descrição da estrutura física, breve descrição da comunidade escolar, localização, caracterização dos profissionais, informações sobre órgãos colegiados e por fim, informações sobre indicadores educacionais: IDEB e avaliações externas.

Quanto à apresentação das atividades desenvolvidas no âmbito do estágio, sejam de observação ou regência, a orientação é que as atividades sejam descritas, discutidas e fundamentadas, reportando-se aos conteúdos trabalhados em sala de aula, descrevendo-se as A estratégias de atuação do professor regente, a utilização de tecnologias e demais instrumentos de promoção da interação durante o ensino remoto. Orienta-se ainda quanto à descrição de aspectos do processo de ensino-aprendizagem no formato de ensino remoto, a interação professor-aluno nos ambientes virtuais, identificando-se metodologias empregadas diante das dificuldades observadas, enfatizando-se, desse modo, as principais aprendizagens e saberes desenvolvidos durante a experiência oportunizada pelos estágios.

Em relação às atividades de apoio e vivências, as orientações sinalizam para a apresentação e discussão das principais atividades desenvolvidas durante os estágios. São atividades apontadas como de apoio e vivências a serem relatadas: planejamentos de aulas com o professor regente, preparação de material didático, participação em momentos de formação docente, rodas de conversas com professores da educação básica, rodas de conversas e entrevistas com egressos do Programa Institucional de Bolsa de Iniciação à Docência - PIBID e Programa Residência Pedagógica - PRP e demais atividades que dialoguem com os processos de formação inicial e de aprendizagem da docência. 


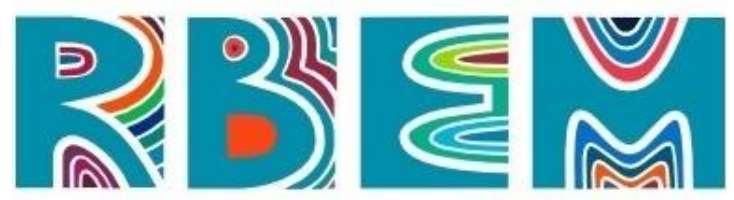

REVISTA BAIANA DE EDUCAÇÃO MATEMÁTICA

Considerando que as atividades de Estágio Supervisionado foram destinadas ao cumprimento de parte da carga-horária no período de atividades remotas, conforme consta no plano de trabalho, e considerando ainda que em algumas turmas havia pendências quanto à integralização da carga-horária das Disciplinas, sugeriu-se, inicialmente, a elaboração de um cronograma, observando as possibilidades de alocação dos estagiários que se encontravam com pendências em disciplinas anteriores, em escolas conveniadas ou no próprio campus, com vistas a integralizar as respectivas cargas horárias no período letivo.

O plano de trabalho para os Estágios Supervisionados no modo remoto emerge como alternativa para dar continuidade ao curso e, embora atenda às prescrições já anunciadas, a proposta sinaliza para "precarizar ainda mais a qualidade do ensino e seguir o calendário a despeito da tragédia vivenciada pela humanidade e sob uma pretensa aparência de normalidade" (MENEZES, MARTILIS e MENDES, 2021, p. 55), uma vez que a realidade de acesso às condições de oferta e realização dessas atividades práticas se mostram, de modo generalizado, igualmente precárias.

No contexto do IFCE campus Cedro muitas foram as iniciativas institucional no sentido de promover o acesso de estudantes ao ensino não presencial. Nesse sentido, registrase além da aquisição de tabletes o lançamento de edital de seleção para Auxílio Internet, destinado a discentes regularmente matriculados em cursos técnicos (integrado e subsequente) e em cursos superiores que aderiram ao ensino remoto. No entanto, assim como observa Santos (2020, p. 21) "a pandemia afeta a todos, mas de diferentes formas [...]”, a oferta das disciplinas de Estágios Supervisionados implicou no contato com escolas de Educação Básica, as quais enfrentam também todas as adversidades impostas pelas condições inadequadas de oferta do ensino remoto emergencial.

O plano destinou-se à prospecção e proposição de estratégias de ofertas dessas disciplinas, porém é preciso salientar os desafios quanto à execução das atividades propostas, ressaltando-se todas as limitações apresentadas quanto ao desenvolvimento do ensino emergencial no modo remoto (SAVIANI, GALVÃO, 2021), o que se percebe não ter sido preocupação relevante para as instituições, diante de diferentes contextos e situações socioeconômicas vividas por alunos em condições de vulnerabilidade social.

\section{Experiências/Memórias, desafios e percepções}




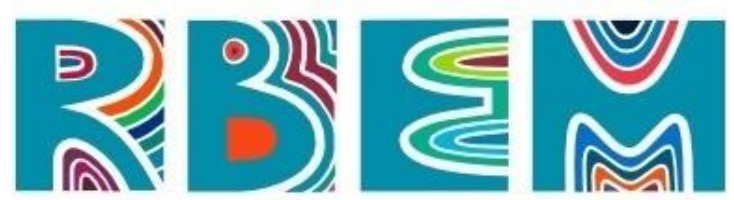

REVISTA BAIANA DE EDUCAÇÃO MATEMÁTICA

Como já anunciado, o Estágio Supervisionado é uma atividade essencial para a formação docente. Além de pressupostos teóricos e práticos, os(as) estudantes se aproximam da realidade educacional e têm a oportunidade de refletir sobre práticas e saberes desenvolvidos no interior da escola, em diálogo com o aporte teórico construído ao longo do curso.

Via de regra, as escolas possuem dinâmicas e rituais cotidianos consubstanciados na conjuntura "do ensino presencial e, de imediato, o que precisa ser desconstruído é o mito da transposição desse cenário para o ensino remoto, tentativa infrutífera, porque os elementos rotineiros são próprios da instituição escola" (SOUZA; FERREIRA, 2020, p.14).

A oferta de ensino remoto emergencial tem exigido muitos esforços de professores, alunos(as) e famílias quanto às condições para a garantia de acesso digital de modo igualitário para todos(as) os(as) estudantes. A premissa da educação como direito, no cenário pandêmico, depende desses pressupostos para o atendimento dos(as) alunos(as), os quais têm sido fortemente negligenciados face ao agravamento do contexto de falta de equidade existente no ensino presencial.

No que diz respeito à formação inicial docente, os(as) licenciandos(as) que aderiram ao ensino no modo remoto estão enfrentando a ausência de vivências na escola na condição de estagiários(as), impedidos do contato com os ritmos, ritos e elementos rotineiros da escola, salutares ao processo de formação inicial de futuros professores. Destaca-se que, no contexto da pandemia, os Estágios Supervisionados em formato remoto limitam ou até impedem a convivência com os(as) professores(as) da educação básica, bem como a interação com o lócus de estágio. A inserção e a experiência no contexto escolar são considerados aspectos basilares para a materialização dos estágios e para a construção da identidade profissional docente.

Nesse sentido, as experiências vivenciadas por estagiários(as) e compartilhadas em momentos de aulas síncronas expressam memórias e percepções quanto aos desafios impostos pelo trabalho remoto, desde a falta de recursos para preparação e realização das aulas à impossibilidade de contato com professores(as) formadores(as) (IES) e professores(as) regentes (Escola Básica), implicando no impedimento da (con)vivência com o ambiente 


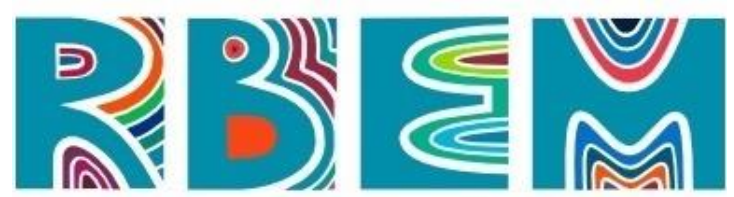

REVISTA BAIANA DE EDUCAÇÃO MATEMÁTICA

pedagógico da escola, limitando as discussões e reflexões sobre saberes que impactam fortemente a formação e o trabalho docente.

Quanto às vivências com professores(as) e alunos(as) de escolas de educação básica, as limitações de acesso e conectividade à internet são questões recorrentes, já que o ensino e o trabalho remoto dependem de tecnologias, ressaltando-se a precariedade ou falta de equipamentos e serviços que permitam o acesso de muitos(as) alunos(as) aos ambientes virtuais de aprendizagem. No Brasil são "mais de 4,5 milhões de brasileiros sem acesso à internet banda larga e mais de 50\% dos domicílios da área rural não possuem acesso à internet. Em uma realidade em que $38 \%$ das casas não possuem acesso à internet e 58\% não têm computador" (ANDES-SN, 2020, p. 14)

Os momentos de diálogos e interlocuções com licenciando(a)s que estão na caminhada do estágio no formato remoto permitem observar o constante sofrimento mútuo, partilhado entre estagiários(as) e professores(as) orientadores(as), reforçando a sensação de frustração no que diz respeito ao desenvolvimento do trabalho formativo, face à realidade que se apresenta para a maioria dos(as) estudantes brasileiros e de grande parte de professores(as).

Diante das experiências com professores(as) de escolas de educação básica, por ocasião da realização de Estágios Supervisionados, licenciandos(as) relatam completa falta de "1 estrutura para o trabalho remoto, destacando-se, principalmente, falta de energia elétrica e de acesso à internet, computadores e aparelhos telefônicos adequados ao acesso a videoaulas nos domicílios dos alunos, além da falta de espaços adequados na casa da maioria desses professores(as) e estudantes(as) (SOLDATELLI, 2020).

$\mathrm{O}$ advento da pandemia do novo coronavírus evidenciou, ainda mais, desigualdades sociais e estruturais do ensino quanto ao "acesso à educação, bem como as relações sociais de trabalho, sua interface com a saúde docente e os sentidos da educação e do trabalho" (SOUZA, et. al. 2021, p. 77).

Mesmo diante de condições adversas, estagiários(as) do curso de Licenciatura em Matemática, a partir de prescrições institucionais, orientações de professores da IES e supervisão de professores(as) da Escola Básica, têm buscado, nos limites do cenário pandêmico, desenvolver e participar de atividades que possibilitem vivenciar experiência profissional docente. Além disso, os momentos de planejamento e elaboração de materiais de 


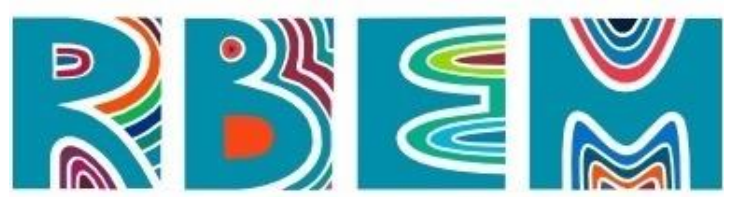

REVISTA BAIANA DE EDUCAÇÃO MATEMÁTICA

suporte à aprendizagem de estudantes, têm sido observados como espaços de aprendizagem e promoção à atualização de professores(as).

Portanto, por necessidade e obrigatoriedade, o ensino/trabalho remoto implicou em acentuada interação de professores(as) com ambientes virtuais de ensino e aprendizagem. Certamente, a educação e a escola não serão as mesmas a partir da pandemia, que embora tenha apresentado diversos contextos de sofrimentos, abriu espaço para múltiplos debates e reflexões atinentes ao contexto educacional e uso de tecnologias, dadas as circunstâncias da pandemia do coronavírus - necessidade de isolamento social e ao processo formativo de professores(as), cujos impactos e perspectivas são pressupostos que orientam a discussão.

\section{Considerações finais}

A realização do presente estudo possibilitou contribuir com a introdução de um debate necessário e oportuno acerca da realização dos estágios supervisionados no formato remoto, no contexto da pandemia, apresentando e discutindo estratégias de ações no caso da Licenciatura em Matemática do IFCE campus Cedro, sinalizando para efeitos dessas alternativas no processo de formação inicial dos futuros professores(as).

As iniciativas se mostram coerentes com as possibilidades do ensino remoto, porém carregam igualmente suas características de desigualdades e assimetrias sociais, no que diz respeito ao acesso aos ambientes virtuais de ensino e aprendizagem, face às condições precárias agravadas pelo contexto da pandemia.

No que diz respeito ao plano de trabalho elaborado com base nas instruções normativas institucionais, observa-se atenção às questões de ordem administrativa, necessárias ao processo de tomada de decisão para a oferta do estágio supervisionado de forma remota, por outro lado, percebe-se, apesar de seu processo de construção coletiva, um distanciamento das realidades que envolvem as práticas efetivas dos estágios, em destaque as condições precárias a que estão dispostos estudantes e professores(as).

Quanto às experiências dos estagiários, os achados apontam para a confirmação desse distanciamento de suas realidades, assim como sugerem limitações relevantes quanto à construção de saberes profissionais, desenvolvimento de competências e habilidades almejadas pelo Projeto Pedagógico do Curso, sobretudo, em decorrência dos obstáculos 


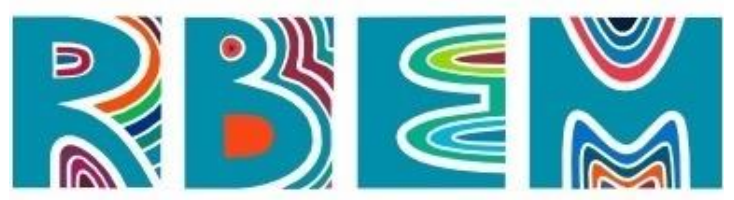

REVISTA BAIANA DE EDUCAÇÃO MATEMÁTICA

expressos pela ausência de vivências e interações com as escolas de educação básica e com seus respectivos atores.

Ao passo em que se evidenciam os aspectos compreendidos como prejudiciais ao processo de formação inicial dos futuros professores, bem como da construção de sua identidade profissional, entende-se imperativo o aprofundamento de estudos que investiguem os efeitos do Estágio Supervisionado no formato remoto em/com licenciandos(as), professores(as) orientadores(as) e professores(as) regentes, assim como escolas de educação básica, no intuito de se refletir sobre as perspectivas futuras que se sucederam e se sucederão ao longo e após esse contexto pandêmico.

\section{Referências}

ALESSI, S. M. et al. A crise sanitária aliada às consequências da pandemia pela Covid-19 no contexto da crise do capital. Universidade e Sociedade, n 67, Ano XXXI, ANDES-SN: janeiro, 2021.

ANDES-SN. Sindicato Nacional dos Docentes das Instituições de Ensino Superior - ANDESSN. Grupo de Trabalho de Política Educacional. Projeto do capital para a educação, volume 4: O ensino remoto e o desmonte do trabalho docente. 2020. Disponível em: https://issuu.com/andessn/docs/cartilha_ensino_remoto. Acesso em: 20 set. 2020.

BARDIN, L. Análise de Conteúdo. 4 ed. Lisboa: Edições 70, 2011.

BRASIL. Ministério da Educação. Conselho Nacional de Educação. Resolução CNE/CP n 2, de 20 de dezembro de 2019. Define as Diretrizes Curriculares Nacionais para a Formação Inicial de Professores para a Educação Básica e institui a Base Nacional Comum para a Formação Inicial de Professores da Educação Básica. Disponível em: http://portal.mec.gov.br/ docman/dezembro-2019-pdf/135951-rcp002-19/file. Acesso em: jun. 2021

BRASIL. Ministério da Educação. Conselho Nacional de Educação/Secretaria Executiva. Súmula do Parecer CNE/CP n. 5/2020. Reorganização do Calendário Escolar e da possibilidade de cômputo de atividades não presenciais para fins de cumprimento da carga horária mínima anual, em razão da Pandemia da COVID-19. Diário Oficial da União, ed. 83, seção 1, Brasília, DF, p. 63, 04 maio 2020. Disponível em: http://www.in.gov.br/en/web/dou//sumula-do-parecer-cne/cp-n-5/2020-254924735. Acesso em: maio de 2020.

BRASIL. Atos do Poder Executivo. Medida Provisória n. 934, de 01 de abril de 2020. Estabelece normas excepcionais sobre o ano letivo da educação básica e do Ensino Superior decorrentes das medidas para enfrentamento da situação de emergência de saúde pública de que trata a Lei n. 13.979, de 6 de fevereiro de 2020. Diário Oficial da União, ed. 63-A, seção 1, Brasília, DF, p. 1, 01 abr. 2020d. Disponível em: http://www.in.gov.br/en/web/dou//medida-provisoria-n-934-de-1-de-abril-de-2020-250710591. Acesso em: abr. 2020. 


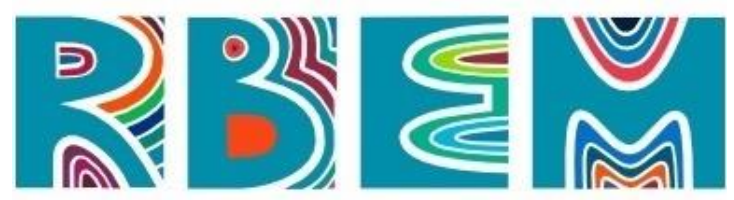

REVISTA BAIANA DE EDUCAÇÃO MATEMÁTICA

BRASIL. Lei nº 11.892, de 29 de dezembro de 2008. Institui a Rede Federal de Educação Profissional, Científica e Tecnológica, cria os Institutos Federais de Educação, Ciência e Tecnologia, e dá outras providências. Diário Oficial da União. Brasília, DF, 29 dez. 2008. Disponível em: http://www. planalto.gov.br/ccivil_03/_ato2007-2010/2008/lei/111892.htm. Acesso em: abr. 2021.

CAPONI, S. Covid-19 no Brasil: entre o negacionismo e a razão neoliberal. Revista Estudos Avançados, 34 (99), 2020. Disponível em: https://www.revistas.usp.br/eav/issue/view/11584. Acesso em: julho de 2021.

FERREIR, L. H. BARBOSA, Andreza Barbosa. Lições de quarentena: limites e possibilidades da atuação docente em época de isolamento social. Práxis Educativa, Ponta Grossa, v. 15, p. 1-24, 2020. Disponível em: https://www.revistas2.uepg.br/ index.php/praxiseducativa. Acesso em: maio de 2021.

GATTI, B. A. ANDRÉ, M. E. D. A. GIMENES, N. A. S. PASSOS, L. F. Um estudo avaliativo do Programa Institucional de Bolsa de Iniciação à Docência (Pibid). São Paulo, FCC/SEP, 2014.

GATTI, B. A. BARRETO, E. S. Sá. ANDRÉ, M. E. D. A. AlMEIDA, P. C. A. Professores do Brasil: novos cenários de formação. Brasília: UNESCO, 2019.

IFCE [INSTITUTO FEDERAL DE EDUCAÇÃO, CIÊNCIA E TECNOLOGIA DO CEARÁ]. Projeto Político Pedagógico do Curso de Licenciatura em Matemática. Cedro, 2012. Disponível em: https://ifce.edu.br/cedro/campus_cedro/cursos/superiores/licenciatura/ matematica/pdf/ppc-matematica. Acesso em: maio de 2021.

IFCE [INSTITUTO FEDERAL DE EDUCAÇÃO, CIÊNCIA E TECNOLOGIA DO CEARÁ]. Ofício Conjunto Circular $n^{o}$ 1/2021 PROEN/PRPI/PROEXT/REITORIA. Desenvolvimento de atividades acadêmicas durante o período de suspensão dos calendários letivos no IFCE. Fortaleza, 24 de março de 2020. Disponível em: https://ifce.edu.br/caucaia/ menu/gt-atividades-letivas/documentos-institucionais/circular-proen-prpi-proext.pdf. Acesso em: fev. de 2021.

IFCE [INSTITUTO FEDERAL DE EDUCAÇÃO, CIÊNCIA E TECNOLOGIA DO CEARÁ]. Ofício Conjunto Circular $n^{o}$ 3/2021 PROEN/REITORIA. Atualização das orientações acerca das atividades de estágio em função dos impactos da Pandemia de COVID19 até a emissão de novas orientações. Fortaleza, 18 de março de 2021. Disponível em: https://ifce.edu.br/aracati/arquivos-diversos/SEI_IFCE2492131OficioCircular.pdf. Acesso em: mar. de 2021.

LIMA, F. J. Desenvolvimento profissional docente e modos de interação no planejamento das atividades do PIBID/Matemática. Curitiba: CRV, 2018.

MARCON, D. Construção do conhecimento pedagógico do conteúdo dos futuros professores de Educação Física. Dissertação de Doutoramento em Ciências do Desporto. Universidade do 


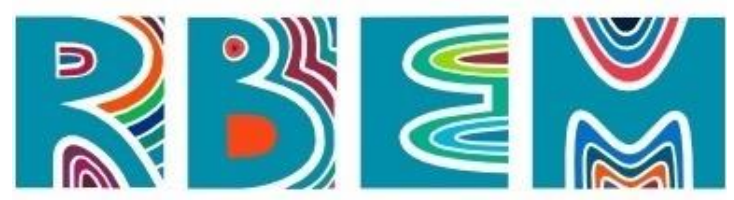

REVISTA BAIANA DE EDUCAÇÃO MATEMÁTICA

Porto, 2011. Disponível em: https://repositorio-aberto.up.pt/bitstream/10216/55556/2/Daniel \%20Marcon\%20\%20Dissertao\%20de\%20doutorado.pdf. Acesso em: ago de 2021.

MENEZES, K. M. G. MARTILIS, L. F. S. MENDES, V. P. S. Os impactos do ensino remoto para a saúde mental do trabalhador docente em tempos de pandemia. Universidade e Sociedade, $\mathrm{n}^{\circ}$ 67, Ano XXXI, ANDES-SN: janeiro, 2021.

OLIVEIRA, J. B. A.; GOMES, M.; BARCELLOS, T. A Covid-19 e a volta às aulas: ouvindo as evidências. Ensaio: Avalição e Políticas Públicas em Educação. Rio de Janeiro, v.28, n.108, p. 555-578, jul./ set. 2020. Disponível em: https://revistas.cesgranrio.org.br/index.php/ ensaio/article/view/2885. Acesso em: jun. de 2021.

OMS. [ORGANIZAÇÃO MUNDIAL DE SAÚDE] - World Health Organization (WHO). Th World Health Report, 2000. Health Systems: Improving Performance. Geneva, Switzerland, 2000. Disponível em: https://www.paho.org/bra. Acesso em: abr. 2020.

PIMENTA, S. G.; LIMA, M. S. L. Estágio e docência: diferentes concepções. Revista Poíesis, v. 3, n. 3 e 4, pp.5-24, 2005/2006. Disponível em: https://www.revistas.ufg.br/ poiesis/article/view/10542/7012. Acesso em: jul de 2021.

PIMENTA, S. G.; LIMA, M. S. L. Estágio e docência. São Paulo: Cortez, 2012.

REIS, A. T. ANDRÉ, M. E. D. A. PASSOS, L. F. Políticas de Formação de Professores no Brasil, pós LDB 9.394/96. Revista brasileira de pesquisa sobre formação de professores. Belo Horizonte, v. 12, n. 23, p. 33-52, jan./abr. 2020. Disponível em: http://www.revformacao docente.com.br. Acesso em: maio de 2021.

SANTOS, B. S. A cruel pedagogia do vírus. Coimbra: Edições Almedina, S.A., 2020.

SAVIANI, D.; GALVÃO, A. C. Educação na pandemia: a falácia do "ensino" remoto. Pandemia da COVID-19: trabalho e saúde docente. Universidade e Sociedade, $\mathrm{n}^{\circ}$ 67, Ano XXXI, ANDES-SN: janeiro, 2021.

SILVA, H. I.; GASPAR, M. Estágio supervisionado:a relação teoria e prática reflexivana formação de professores do cursode Licenciatura em Pedagogia. Revista Brasileira de Estudos Pedagógicos. Brasília, v. 99, n. 251, p. 205-221, jan./abr. 2018.

SOLDATELlI, R. Processo de adoecimento de professores amplia durante pandemia. Esquerda Marxista. Corrente Marxista Internacional, 2020. Disponível em: https://www. marxismo.org.br/processo-de-adoecimento-de-professores-amplia-durante-pandemia/. Acesso em: 24 set. 2020.

SOUZA, E. Â.; ANTUNES, C.; PEDROSO, G. ALCANTARA, A. C. A pandemia do novo coronavírus, Covid-19 e a relação trabalho e saúde na educação. Pandemia da COVID-19: trabalho e saúde docente. Universidade e Sociedade 67 Ano XXXI - Nº 67 - janeiro de 2021.

SOUZA, M. F.; FERREIRA, L. G. Ensino remoto emergencial e o estágio supervisionado nos 


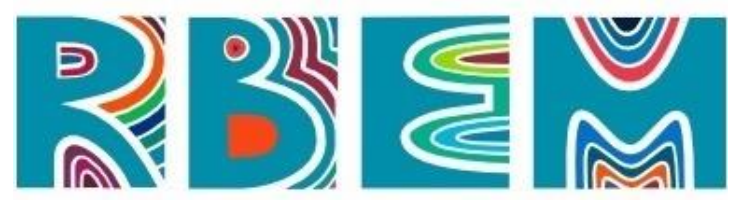

cursos de licenciatura no cenário da pandemia COVID 19. Rev. Tempos e Espaços em Educação. v.13, n. 32, e-14290, jan./dez.2020.

UNESCO. Disponível em https://en.unesco.org/covid19/educationresponse. Acesso em: abr. de 2020.

YIN, R. K. Estudo de caso: planejamento e métodos. Porto Alegre: Bookman, 2005.

Artigo submetido em: 29/07/2021

Artigo aceito em: 16/08/2021 